\title{
Effect of Melatonin and Its Analogs on Tear Secretion
}

\author{
Francisco Javier Navarro Gil, Fernando Huete-Toral, Almudena Crooke, \\ Carmen Olalla Dominguez Godinez, Gonzalo Carracedo, and Jesús Pintor \\ Departamentos de Optometría y Visión (F.J.N.G., C.O.D.G., G.C.) and Bioquímica y Biología Molecular (F.H.-T., A.C., J.P.), \\ Facultad de Óptica y Optometría, Universidad Complutense de Madrid, Madrid, Spain
}

Received April 17, 2019; accepted July 30, 2019

\begin{abstract}
Melatonin has been shown to enhance tear secretion associated with dinucleotide diadenosine tetraphosphate. This study investigated the isolated action of melatonin and its analogs, agomelatine, N-butanoyl-2-(2-methoxy-6H-isoindolo[2,1-a]indol-11-yl) ethanamine (IIK7), and 5-methoxycarbonylamino- $N$-cetyltryptamine (5-MCA-NAT) (10 $\mu \mathrm{l}$ at $100 \mu \mathrm{M})$, on tear secretion when applied topically in the rabbit cornea and its relationship with the melatonin MT1, MT2, and MT3/quinone reductase QR2 receptors. The results showed a significant increase in tear secretion, with a maximal effect at 60 minutes for the agonists $(138.9 \% \pm 6.5 \%, 128.9 \% \pm 6.4 \%$, and $120.0 \% \pm 5.2 \%$, respectively; $P<0.05 ; 100 \%$ control) but not for melatonin $(101.6 \% \pm 7.9 \% ; P>0.05)$. Agonist action was tested combined with the antagonists DH97 (MT2 selective), prazosin (MT3/QR2 inhibitor), and luzindole (nonselective MT membrane receptor) $(10 \mu \mathrm{l}$ at $100 \mu \mathrm{M})$. DH97 reversed the effect of agomelatine, IIK7, and 5-MCA-NAT up to $30.85 \% \pm 7.6 \%, 108 \% \pm 7.2 \%$, and $87.01 \% \pm 7.6 \%$, respectively $(P<0.05 ; 100 \%$ control). Luzindole antagonized agomelatine and 5-MCA-NAT up to $67.35 \% \pm$ $7.6 \%$ and $92.12 \% \pm 8 \%$, respectively $(P<0.05)$. Prazosin only
\end{abstract}

reversed 5-MCA-NAT action up to $84.2 \% \pm 7.7 \%(P<0.05)$. These results suggest different pathways for the agonists to act through MT membrane receptors. Therefore, agomelatine, IIK7, and 5-MCA-NAT act through MT membrane receptors as secretagogues of tear secretion, and these analogs could be considered excellent therapeutic candidates for dry eye treatment.

\section{SIGNIFICANCE STATEMENT}

Currently, dry eye with aqueous deficit is treated by adding artificial tears palliatively. This study shows that topical installation of three melatonin analogs (agomelatine, IIK7, and 5-MCANAT), but not melatonin, in therapeutic doses in the rabbit cornea significantly increases tear production, acting through different melatonin membrane receptor subtypes. Therefore, this study suggests that melatoninergic compounds could be considered excellent therapeutic candidates for dry eye treatment and ocular surface diseases occurring with a reduction in tear production.

\section{Introduction}

Melatonin is a neurohormone, released mainly from the pineal gland (Stehle et al., 2011), that is involved in the control of various physiologic actions, many of which are related with the regulation of circadian rhythms (Pandi-Perumal et al., 2006). The ability to synthesize and release melatonin is not an exclusive feature of the pineal gland. Melatonin production has been discovered in the orbital cavity and some eye areas such as the retina (Cardinali and Rosner, 1971; AlarmaEstrany and Pintor, 2007), the ciliary body (Martin et al., 1992; Alarma-Estrany and Pintor, 2007), and the lens (Alkozi et al., 2018). Melatonin was also recently found in human tears (Carracedo et al., 2017).

The relationship between melatonin levels and some functions in the eye (Samples et al., 1988), such as the fluctuation of intraocular pressure (Rowland et al., 1981; Liu et al., 2011),

This study was supported in part by the Instituto de Salud Carlos III through the Redes Temáticas de Investigación Cooperativa en Salud [Grant RD16/0008/0001]

In memory of Jesús Pintor (deceased)

https://doi.org/10.1124/jpet.119.259192. is well known. In this sense, the application of melatonin or any of its analogs has been proposed as a therapeutic agent for different ocular conditions (Pintor et al., 2001, 2003; Serle et al., 2004; Alarma-Estrany et al., 2008, 2011; Ismail and Mowafi, 2009; Crooke et al., 2013; Colligris et al., 2014).

Some studies have demonstrated that the use of melatonin on the ocular surface, combined with the dinucleotide diadenosine tetraphosphate, instilled in the eye of New Zealand white rabbits caused a significant increase in tear secretion (Hoyle et al., 2006).

Melatonin exerts many of its actions by means of membrane receptors, termed melatonin receptors, divided into MT1, MT2, and MT3 (Alarma-Estrany and Pintor, 2007; Dubocovich et al., 2010). New studies identify MT3 with the enzyme quinone reductase QR2 (Boutin and Ferry, 2019). Beyond these findings, melatonin receptors on the ocular surface have been identified in structures such as the cornea in different species (Wiechmann and Rada, 2003). In particular, MT2 receptors have been described in the cornea of New Zealand white rabbits (Crooke et al., 2015). Melatonin receptors were found in the lachrymal gland, and the effect of melatonin, in combination with dinucleotide diadenosine tetraphosphate,

ABBREVIATIONS: 5-MCA-NAT, 5-methoxycarbonylamino- $N$-cetyltryptamine; IIK7, N-butanoyl-2-(2-methoxy-6H-isoindolo[2,1-a]indol-11-yl) ethanamine; MT, melatonin receptor; QR, quinone reductase. 
on increased tear secretion was previously reported (Hoyle et al., 2006).

This study aimed to characterize the effect of melatonin and its analogs (agomelatine, 5MCA-NAT, and IIK7) on tear secretion in New Zealand rabbits.

\section{Materials and Methods}

Materials. Melatonin, 5-methoxycarbonylamino- $N$-acetyltryptamine (5MCA-NAT), $\quad N$-butanoyl-2-(2-methoxy-6H-isoindolo[2,1- $a$ ]indol-11-yl) ethanamine (IIK7), prazosin, DH97, and luzindole were purchased from Tocris (Bristol, UK) and agomelatine was purchased from Santa Cruz Biotechnology Inc. (Dallas, TX). All of the compounds were formulated in isotonic saline containing 1\% DMSO from Sigma-Aldrich (St. Louis).

Animals. Male New Zealand white rabbits weighing 3 to $4 \mathrm{~kg}$ were placed in individual cages with free access to food and water and were subjected to regular light/dark cycles (12 hours). All experiments were performed according to the Association for Research in Vision and Ophthalmology Statement for the Use of Animals in Ophthalmic and Vision Research and to European Directive 2010/63/EU.

Measurement of Tear Secretion. Tear secretion was measured with the Schirmer test, according to the protocol described by van Bijsterveld (van Bijsterveld, 1969), using Whatman no. 51 paper strips (Schirmer strips; Whatman, Maidstone, UK) placed in the inferior lid margin of the eye for 5 minutes. Tear secretion was measured as the length (in millimeters) of the strip wetted by the tears.

Pharmacological Experiments. Control experiments were performed by applying $10 \mu$ l saline solution $(0.9 \% \mathrm{NaCl})$ containing $1 \%$ DMSO instilled 15 minutes before any of the other compounds were used. Melatonin and its agonists were instilled in a volume of $10 \mu \mathrm{l}$ at $100 \mu \mathrm{M}$. Tear secretion measurements were performed at 5 , 15,60 , and 120 minutes after their application $(n=24)$. Melatonin receptor antagonists, DH97 (a MT2 selective antagonist), prazosin

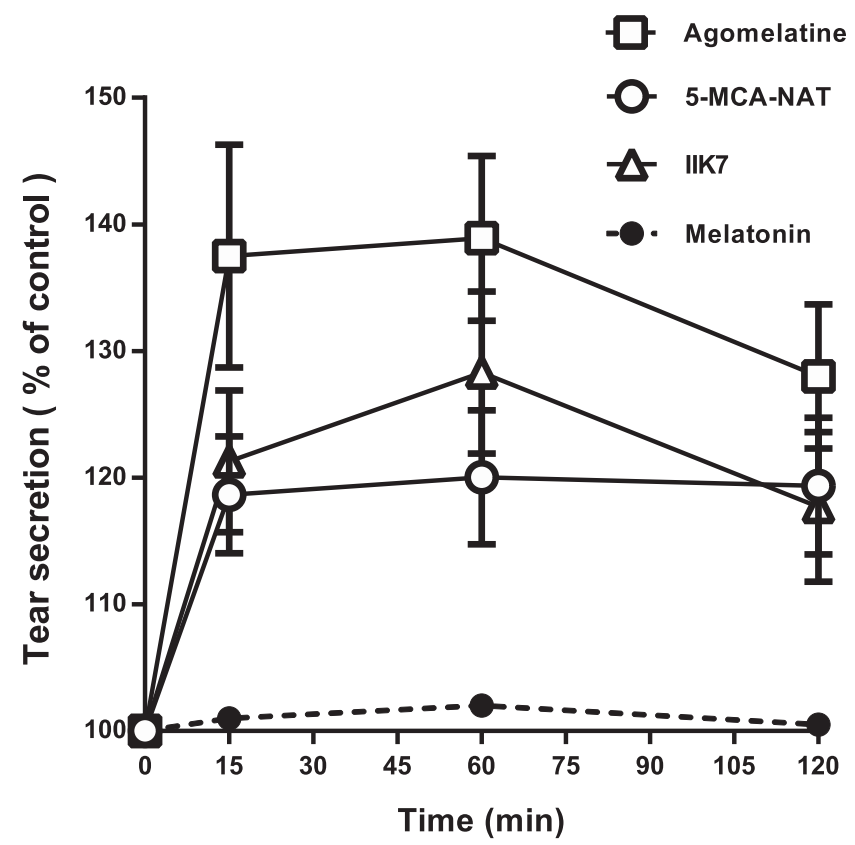

Fig. 1. Time course. Effect of melatonin and analogs on tear secretion tested at 5, 15, 30,60, and 120 minutes. Data are presented as the mean \pm S.E.M. Topical single applications of the compounds $(10 \mu \mathrm{l}$ at $100 \mu \mathrm{M} ; n=24)$. A significant increase in tear secretion was observed in the case of agomelatine, IIK7, and 5-MCA-NAT $(P<0.05$, one-way ANOVA for related samples). The topical application of melatonin did not modify tear secretion during the experimental time $(P>0.05$, one-way ANOVA for related samples).
(MT3/QR2 inhibitor), and luzindole (a nonselective melatonin receptor antagonist), were applied at $100 \mu \mathrm{M}(10 \mu \mathrm{l})$ and instilled 15 minutes before the application of the agonists, which were instilled at $100 \mu \mathrm{M}$ $(n=10)$.

To determine the concentration-response curves, different concentrations of melatonin, agomelatine, IIK7, and 5-MCA-NAT were tested according to the previously described method. Concentrations tested varied from $1 \mu \mathrm{M}$ to $1 \mathrm{mM}(n=10)$.

Statistical Analysis. Statistical analysis was performed using SPSS Statistics 23 software (IBM, Chicago, IL). All data are presented as the mean \pm S.E.M. The normal distribution of all variables for each experiment was assessed with the Shapiro-Wilk test. Statistical differences between baseline and postinstillation for all treatments were calculated using the $t$ test for related samples. In addition, oneway ANOVA for related samples was used to analyze the trend in dose-response experiments. Plotting and fitting were carried out with Prism 6 GraphPad software (GraphPad Software, La Jolla, CA). $P<0.05$ was considered statistically significant.

\section{Results}

Effect of Melatonin and Analogs on Tear Secretion. To study the possible effect of melatonin and its analogs on tear secretion, single applications of these compounds ( $10 \mu \mathrm{l}$ at $100 \mu \mathrm{M})$ were tested on New Zealand rabbits. The topical application of melatonin did not modify tear secretion during the experimental time $(101.6 \% \pm 7.9 \%$ at 60 minutes, Fig. 1$)$ and was not statistically significant $(P>0.05, t$ test for related samples). However, a significant increase in tear secretion was

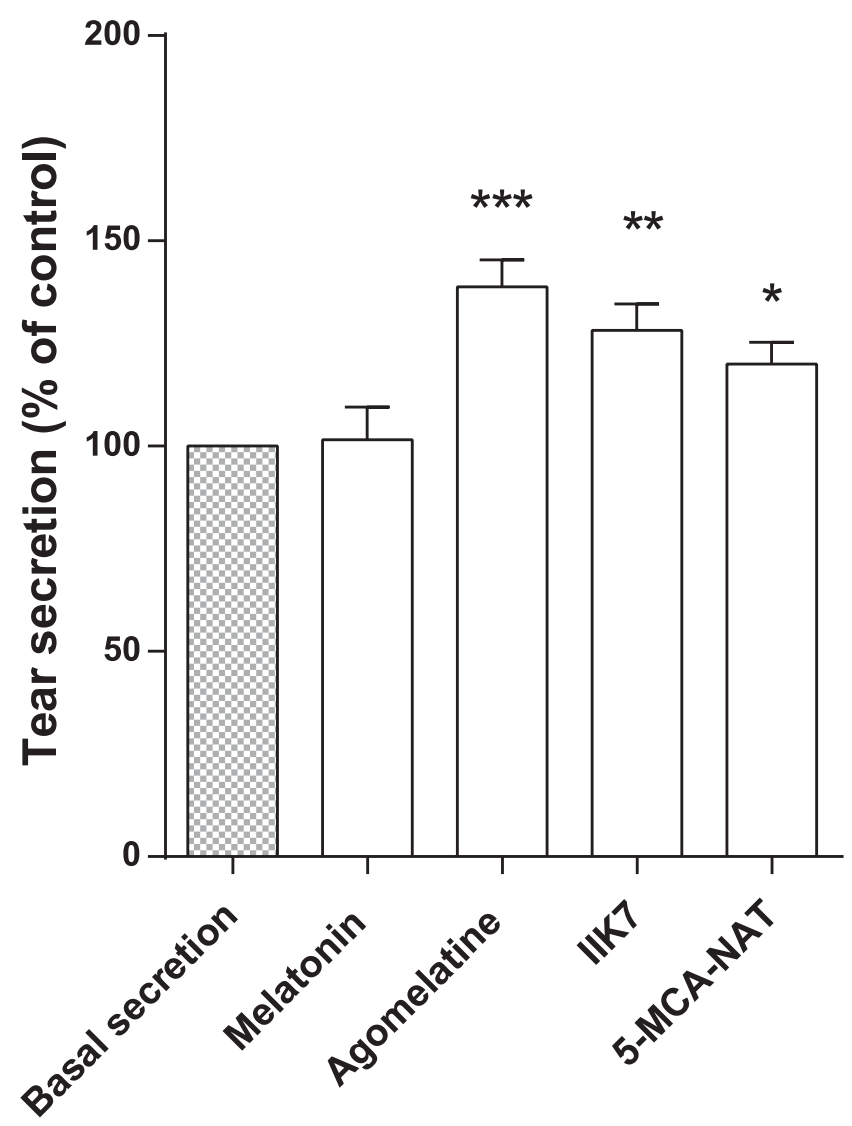

Fig. 2. Maximal effect of melatonin and its analogs on tear secretion at 60 minutes. Data are presented as the mean \pm S.E.M. $P<0.05$ was considered statistically significant. Compounds were tested $10 \mu \mathrm{l}$ at $100 \mu \mathrm{M}(n=24)$. $* P<0.05 ; * * P<0.01 ; * * * P<0.001(t$ test for related samples). 
clearly observed, which was maximal above the control value (100\% basal production) when agomelatine, IIK7, or 5-MCANAT was assayed 1 hour after their topical application $(P<0.05$, $t$ test for related samples) (Fig. 1). The values obtained (Fig. 2) were $138.9 \% \pm 6.5 \%$ for agomelatine, $120.0 \% \pm 5.2 \%$ for 5 -MCANAT, and $128.3 \% \pm 6.4 \%$ for IIK7 $(n=24 ; P<0.05, t$ test for related samples).

Dose-Response Studies. Since agomelatine, 5-MCANAT, and IIK7 were able to increase tear secretion when tested at a single dose, the three compounds were tested at several concentrations ranging from $1 \mu \mathrm{M}$ to $1 \mathrm{mM}$. As can be seen in Fig. 3, the melatonin analogs presented sigmoid curves. Agomelatine presented a maximal secretion of $129.9 \% \pm 8.2 \%$ above the control value (100\% basal production) and a affinity index (pD2) of $4.28 \pm 0.06\left(\mathrm{EC}_{50}\right.$ value of 52.1 $\mu \mathrm{M}, n=10)$. On the other hand, 5-MCA-NAT presented a maximal effect of $135.7 \% \pm 7.8 \%$ over the control and a pD2 of $4.0 \pm 0.02\left(\mathrm{EC}_{50}\right.$ value of $\left.99.5 \mu \mathrm{M}, n=10\right)$. Finally, IIK7 presented a maximal effect of $127.6 \% \pm 2.5 \%$ with a pD2 value of $4.15 \pm 0.07\left(\mathrm{EC}_{50}\right.$ value of $\left.69.2 \mu \mathrm{M}, n=10\right)(P<0.05$, one-way ANOVA test for related samples for all melatonin analogs tested). Melatonin was also tested, at the same range of concentrations, to see whether it was able to induce tear secretion. As observed in Fig. 3, only at very high concentrations did melatonin induce a very small increase in tearing; nonetheless, it was not possible to fit a doseresponse curve $(P<0.05$, one-way ANOVA test for related samples).

Antagonist/Inhibitor Studies. As mentioned previously, melatonin and its analogs display their actions on MT1, MT2, or MT3/QR2 melatonin receptors. To investigate the receptor by which melatonin agonists were acting, the antagonists luzindole (a nonselective melatonin receptor antagonist), DH97 (a selective MT2 receptor antagonist), and prazosin (MT3/QR2 inhibitor) were tested.

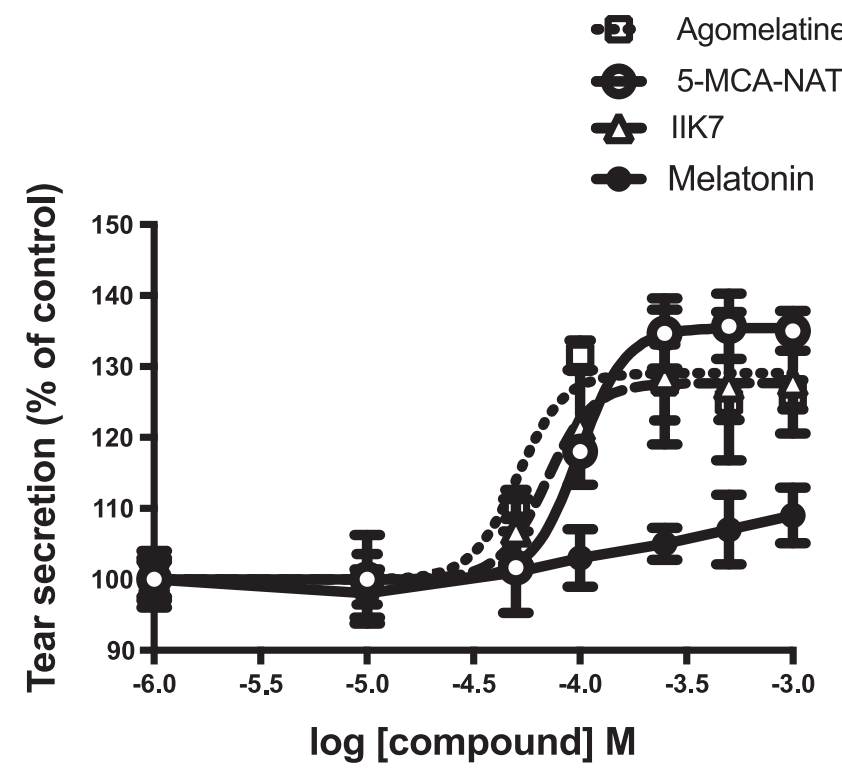

Fig. 3. Dose-response studies. Compounds were tested at several concentrations ranging from $1 \mu \mathrm{M}$ to $1 \mathrm{mM}(n=10)$. Data are presented as the mean \pm S.E.M. The three analogs presented sigmoid curves $(P<0.05$, oneway ANOVA for related samples). In the case of melatonin, it was not possible to fit a dose-response curve $(P>0.05$, one-way ANOVA for related samples).
When agomelatine was assayed in the presence of the three mentioned antagonists, it was possible to observe that only two were able to significantly reverse agomelatine action, the most active being DH97 (Fig. 4). Luzindole reversed the agomelatine effect on the control value (100\% basal) up to $67.35 \% \pm 6.7 \%$, whereas DH97 antagonized up to $30.85 \% \pm 7.6 \%(n=10$; $P<0.05, t$ test for related samples). When the results of the decrease below the control were compared with those obtained from their maximal agonist effect $(138.9 \% \pm 6.5 \%)$, the differences were much more significant, with decrease values of $71.6 \% \pm 6.7 \%$ and $108.1 \% \pm 7.1 \%$, respectively $(P<0.05, t$ test for related samples). However, prazosin was not able to antagonize the agomelatine effect on tear secretion $(P>0.05, t$ test for related samples). When the same experiments were carried out with IIK7 (as shown in Fig. 5), only DH97 was able to significantly revert the effect of this melatonin agonist up to $108 \% \pm 7.2 \%$ above the control $(n=10 ; P<0.05, t$ test for related samples), which is $20.9 \% \pm 5.5 \%$ with respect to its maximal agonist action $(128.9 \% \pm 6.4 \%)$. Finally, when 5-MCANAT was tested with prazosin, DH97, and luzindole (Fig. 6), a similar significant antagonistic and inhibition effect was noticed $(84.2 \% \pm 7.7 \%, 87.01 \% \pm 7.7 \%$, and $92.12 \% \pm 8 \%$, respectively) ( $n=10 ; P<0.05, t$ test for related samples). The decrease compared with its agonist action $(120.0 \% \pm 5.2 \%)$ was $35.8 \% \pm 6.3 \%, 33 \% \pm 6.3 \%$, and $27.9 \% \pm 4.5 \%$ for the three antagonists.

\section{Discussion}

In this work, the effect of melatonin receptor agonists agomelatine, 5-MCA-NAT, and IIK7 on tear secretion was

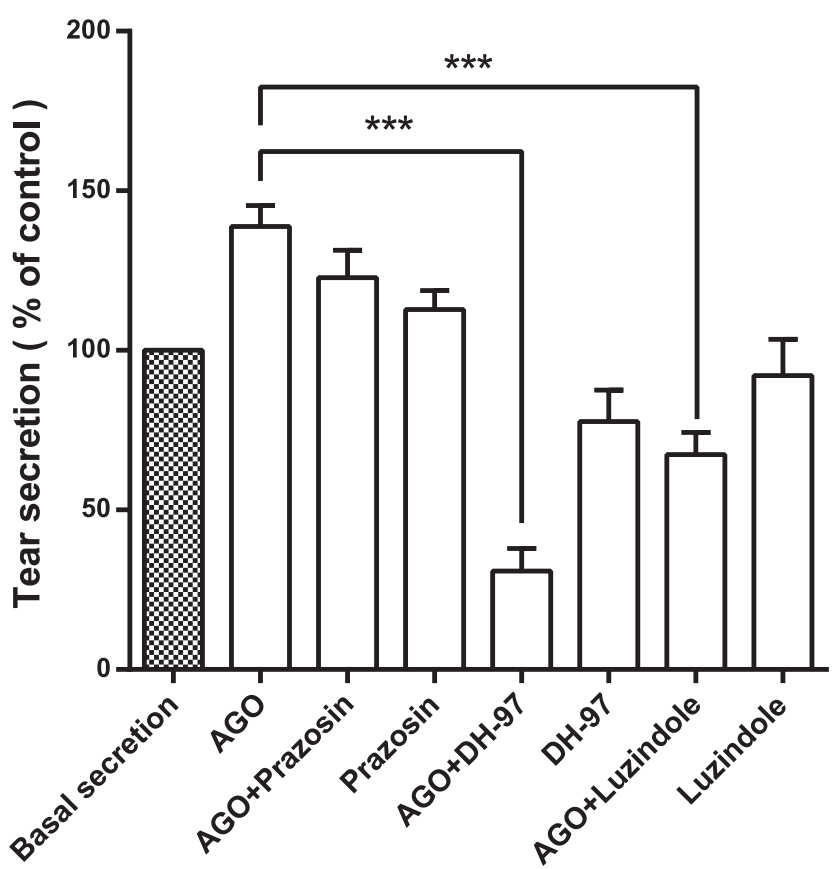

Fig. 4. Combined action of agomelatine (AGO) with antagonists prazosin, DH-97, and luzindole at 60 minutes. Data are presented as the mean \pm S.E.M. $P<0.05$ was considered statistically significant. Antagonists were applied at $100 \mu \mathrm{M}(10 \mu \mathrm{l})$ and instilled 15 minutes before the application of the agonist $(10 \mu \mathrm{l}$ at $100 \mu \mathrm{M})(n=10)$. $* * * P<0.001$ ( $t$ test for related samples) (Cardinali and Rosner, 1971; Alarma-Estrany and Pintor, 2007; Alarma-Estrany et al., 2008, 2011; Alkozi et al., 2018; Boutin and Ferry, 2019). 


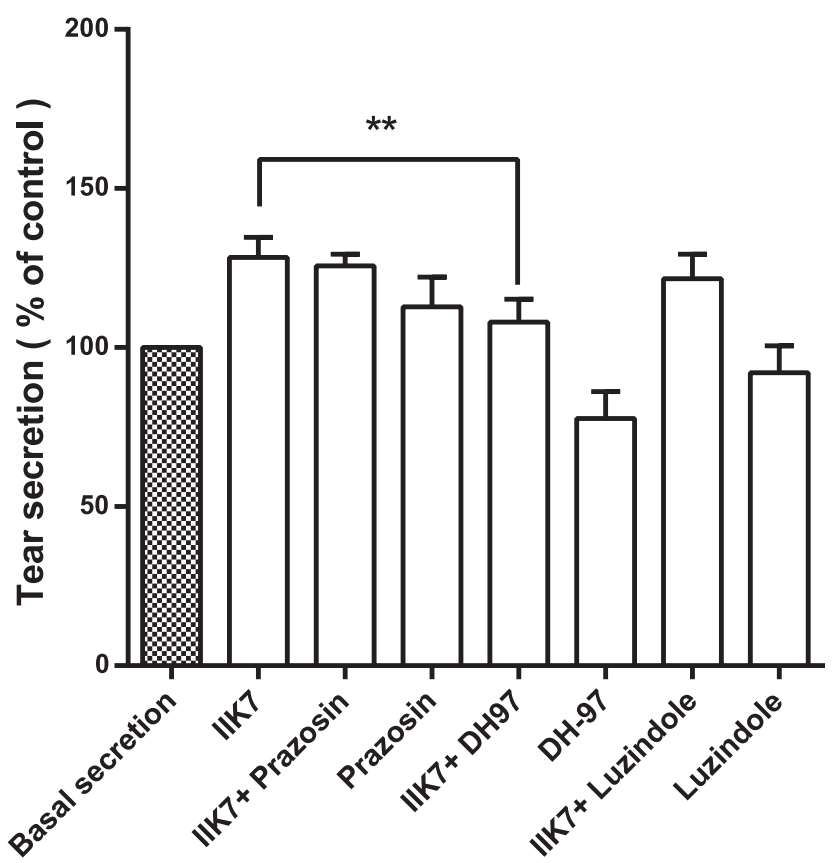

Fig. 5. Combined action of IIK7 with antagonists prazosin, DH-97, and luzindole at 60 minutes. Data are presented as the mean \pm S.E.M. $P<0.05$ was considered statistically significant. Antagonists were applied at $100 \mu \mathrm{M}(10 \mu \mathrm{l})$ and instilled 15 minutes before the application of the agonist $(10 \mu \mathrm{l}$ at $100 \mu \mathrm{M})(n=10) .{ }^{* *} P<0.01$ ( $t$ test for related samples).

investigated. The results demonstrate that the three analogs are effective in inducing tear secretion in New Zealand rabbits but they did not activate the same melatonin receptor subtypes, as shown by the antagonist/inhibitor studies. Whereas the IIK7 agonist acted in a very specific manner through MT2 receptors because its action was only blocked in the presence of DH97 (see Fig. 5), the results obtained with 5-MCA-NAT do not allow us to determine a specific mechanism of action. In that case, the effect of 5-MCA-NAT was partially inhibited in the presence of the three antagonists/ inhibitors in a similar way (see Fig. 6). This is likely due to the action as a partial agonist on MT1/MT2 of 5-MCA-NAT (Vincent et al., 2010). The action of agomelatine is reversed by two of the three antagonists/inhibitors (see Fig. 4), showing an important decrease action with prazosin but without statistical significance and especially with DH97 This suggesting a two-way action through the receptors MT2 and MT3/QR2. Interestingly, a study by Boutin and Ferry (2019) identified MT3 with QR2. Perhaps the nature of this enzyme is responsible for the controversial action attributed to the MT3 receptor.

An interesting point to consider is whether the combination of two agonists would be more effective in the increase in tear secretion than the individual action. Unpublished experiments carried out in our laboratory demonstrated that the combination of 5-MCA-NAT and IIK7 only increased tearing $5 \%$ above the values obtained by these two compounds individually. This lack of an additive effect is likely a consequence of both agonists using melatonin in mainly the same receptors, and only 5-MCA-NAT may be acting through MT3/QR2 since its effect is blocked by prazosin (Huete-Toral et al., 2015). In this sense, Chu and Candia (1988) demonstrated that prazosin interplays with tears by $\alpha 2$-adrenergic receptors in a frog cornea model. However, this study showed

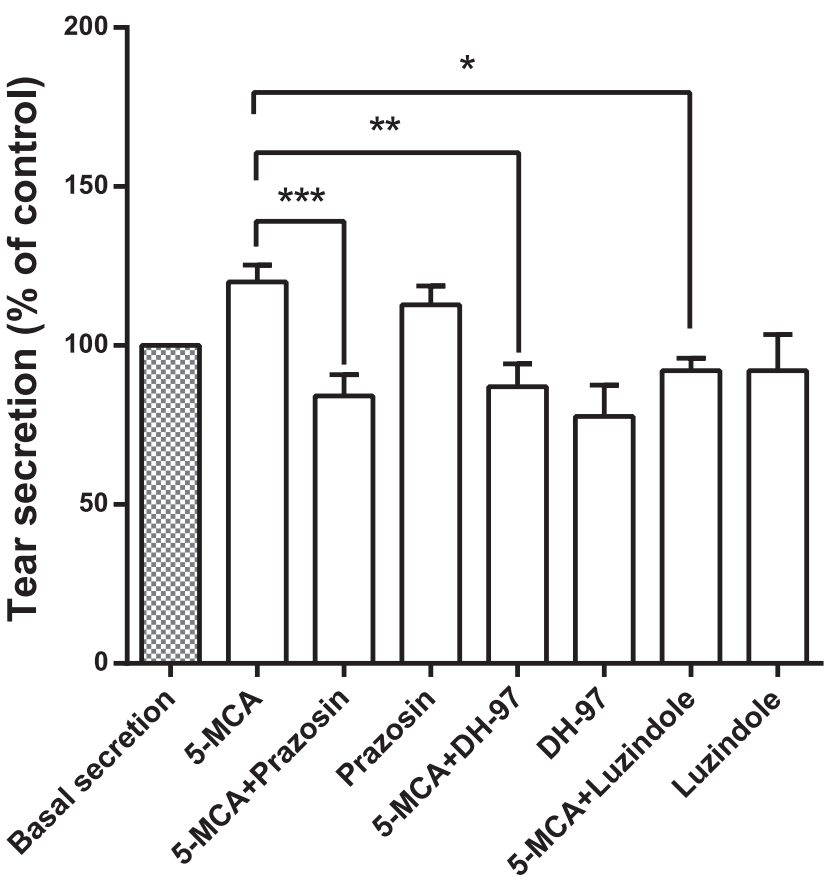

Fig. 6. Combined action of 5-MCA-NAT with antagonists prazosin, DH97 , and luzindole at 60 minutes. Data are presented as the mean \pm S.E.M. $P<0.05$ was considered statistically significant. Antagonists were applied at $100 \mu \mathrm{M}(10 \mu \mathrm{l})$ and instilled 15 minutes before the application of the agonist $(10 \mu \mathrm{l}$ at $100 \mu \mathrm{M})(n=10) . * P<0.05 ; * * P<0.01 ; * * * P<0.001(t$ test for related samples).

no significant difference between the group treated with prazosin and the basal control (100\%).

The high affinity of melatonin analogs compared with melatonin itself is an interesting aspect, indicating that rather than using melatonin to induce tear secretion, it would be better to use its analogs. This is not the only case; indeed, the compound 5-MCA-NAT has demonstrated a more robust effect in reducing intraocular pressure in rabbits than melatonin does (Pintor et al., 2003). On the ocular surface, the ability of melatonin to accelerate corneal wound healing is enhanced by the MT2 receptor agonist IIK7 (Crooke et al., 2015). In this work, agonists of melatonin receptors produced a significant increase in tear production, the effect of which was dose dependent. Melatonin did present an apparent concentrationresponse behavior, which was only visible at a high concentration, in clear contrast with the effect of its analogs. Such differences may be attributable to the best affinity of the analogs acting on melatonin receptors (Alkozi et al., 2018).

Some comments can be made concerning which of the melatonin analogs would be the best candidate as a treatment for ocular dryness. Although agomelatine produces the most robust effect at $100 \mu \mathrm{M}$ (see Figs. 1 and 2), concentrationresponse curves showed that 5-MCA-NAT could increase tearing $10 \%$ more than agomelatine or IIK7 but the dose is increased to $300 \mu \mathrm{M}$ or greater. Thinking about the idea of using any of these compounds to treat dry eye, as commented, little is known of 5-MCA-NAT and IIK7 regarding toxic effects, side effects, and safety in general, whereas agomelatine is a compound that is already on the pharmaceutical market for other purposes (Taylor et al., 2014; Levitan et al., 2015). Nonetheless, it is important to point out that agomelatine can also act over other receptors different from melatonin 
receptors, such as 5HT2c (Racagni et al., 2011). Therefore, taking into account the results found in this study, melatonin agonists that trigger tear secretion without interfering with other receptors (e.g., 5-MCA-NAT or IIK7) would be better choices.

In summary, melatonin analogs can induce a significant increase in tear secretion in New Zealand rabbits. This is a relevant issue since there is currently no pharmaceutical compound available to treat dry eye, although artificial tears that aim to relieve patients' symptoms are commercially available (Pucker et al., 2016). Therefore, this study suggests that melatoninergic compounds are putative agents for the treatment of ocular surface diseases occurring with a reduction in tear production.

\section{Authorship Contributions}

Participated in research design: Navarro Gil, Huete-Toral, Pintor. Conducted experiments: Navarro Gil, Huete-Toral.

Contributed new reagents or analytic tools: Crooke, Dominguez Godinez.

Performed data analysis: Navarro Gil, Huete-Toral, Carracedo, Pintor.

Wrote or contributed to the writing of the manuscript: Navarro Gil, Huete-Toral, Carracedo, Pintor.

\section{References}

Alarma-Estrany P, Crooke A, Mediero A, Peláez T, and Pintor J (2008) Sympathetic nervous system modulates the ocular hypotensive action of MT2-melatonin receptors in normotensive rabbits. J Pineal Res 45:468-475.

Alarma-Estrany P, Guzman-Aranguez A, Huete F, Peral A, Plourde R Jr, Pelaez T, Yerxa B, and Pintor J (2011) Design of novel melatonin analogs for the reduction of intraocular pressure in normotensive rabbits. J Pharmacol Exp Ther 337:703-709.

Alarma-Estrany P and Pintor J (2007) Melatonin receptors in the eye: location, second messengers and role in ocular physiology. Pharmacol Ther 113:507-522.

Alkozi HA, Sánchez Montero JM, Doadrio AL, and Pintor J (2018) Docking studies for melatonin receptors. Expert Opin Drug Discov 13:241-248.

Boutin JA and Ferry G (2019) Is there sufficient evidence that the melatonin binding site $\mathrm{MT}_{3}$ is quinone reductase 2? J Pharmacol Exp Ther 368:59-65.

Cardinali DP and Rosner JM (1971) Retinal localization of the hydroxyindole-Omethyl transferase (HIOMT) in the rat. Endocrinology 89:301-303.

Carracedo G, Carpena C, Concepción P, Díaz V, García-García M, Jemni N, Lledó VE, Martín M, Pastrana C, Pelissier R, et al. (2017) Presence of melatonin in human tears. J Optom 10:3-4

Chu TC and Candia OA (1988) Role of alpha 1- and alpha 2-adrenergic receptors in Cl- transport across frog corneal epithelium. Am J Physiol 255:C724-C730.

Colligris B, Alkozi HA, and Pintor J (2014) Recent developments on dry eye disease treatment compounds. Saudi J Ophthalmol 28:19-30.

Crooke A, Guzman-Aranguez A, Mediero A, Alarma-Estrany P, Carracedo G, Pelaez T, Peral A, and Pintor J (2015) Effect of melatonin and analogues on corneal wound healing: involvement of Mt2 melatonin receptor. Curr Eye Res 40:56-65.

Crooke A, Huete-Toral F, Martínez-Águila A, Martín-Gil A, and Pintor J (2013) Melatonin and its analog 5-methoxycarbonylamino-N-acetyltryptamine potentiate adrenergic receptor-mediated ocular hypotensive effects in rabbits: significance for combination therapy in glaucoma. $J$ Pharmacol Exp Ther 346:138-145.
Dubocovich ML, Delagrange P, Krause DN, Sugden D, Cardinali DP, and Olcese J (2010) International Union of Basic and Clinical Pharmacology. LXXV. Nomenclature, classification, and pharmacology of $\mathrm{G}$ protein-coupled melatonin receptors. Pharmacol Rev 62:343-380.

Hoyle CH, Peral A, and Pintor J (2006) Melatonin potentiates tear secretion induced by diadenosine tetraphosphate in the rabbit. Eur J Pharmacol 552: 159-161.

Huete-Toral F, Crooke A, Martínez-Águila A, and Pintor J (2015) Melatonin receptors trigger cAMP production and inhibit chloride movements in nonpigmented ciliary epithelial cells. J Pharmacol Exp Ther 352:119-128.

Ismail SA and Mowafi HA (2009) Melatonin provides anxiolysis, enhances analgesia, decreases intraocular pressure, and promotes better operating conditions during cataract surgery under topical anesthesia. Anesth Analg 108:1146-1151.

Levitan MN, Papelbaum M, and Nardi AE (2015) Profile of agomelatine and its potential in the treatment of generalized anxiety disorder. Neuropsychiatr Dis Treat 11:1149-1155.

Liu H, Fan S, Gulati V, Camras LJ, Zhan G, Ghate D, Camras CB, and Toris CB (2011) Aqueous humor dynamics during the day and night in healthy mature volunteers. Arch Ophthalmol 129:269-275.

Martin XD, Malina HZ, Brennan MC, Hendrickson PH, and Lichter PR (1992) The ciliary body--the third organ found to synthesize indoleamines in humans. Eur J Ophthalmol 2:67-72.

Pandi-Perumal SR, Srinivasan V, Maestroni GJ, Cardinali DP, Poeggeler B, and Hardeland R (2006) Melatonin: nature's most versatile biological signal? FEBS $J$ 273:2813-2838.

Pintor J, Martin L, Pelaez T, Hoyle CH, and Peral A (2001) Involvement of melatonin MT(3) receptors in the regulation of intraocular pressure in rabbits. Eur $J$ Pharmacol 416:251-254.

Pintor J, Peláez T, Hoyle CH, and Peral A (2003) Ocular hypotensive effects of melatonin receptor agonists in the rabbit: further evidence for an MT3 receptor. Br J Pharmacol 138:831-836.

Pucker AD, Ng SM, and Nichols JJ (2016) Over the counter (OTC) artificial tear drops for dry eye syndrome. Cochrane Database Syst Rev 2:CD009729.

Racagni G, Riva MA, Molteni R, Musazzi L, Calabrese F, Popoli M, and Tardito D (2011) Mode of action of agomelatine: synergy between melatonergic and 5-HT2C receptors. World J Biol Psychiatry 12:574-587.

Rowland JM, Potter DE, and Reiter RJ (1981) Circadian rhythm in intraocular pressure: a rabbit model. Curr Eye Res 1:169-173.

Samples JR, Krause G, and Lewy AJ (1988) Effect of melatonin on intraocular pressure. Curr Eye Res 7:649-653.

Serle JB, Wang RF, Peterson WM, Plourde R, and Yerxa BR (2004) Effect of 5-MCANAT, a putative melatonin MT3 receptor agonist, on intraocular pressure in glaucomatous monkey eyes. J Glaucoma 13:385-388.

Stehle JH, Saade A, Rawashdeh O, Ackermann K, Jilg A, Sebestény T, and Maronde E (2011) A survey of molecular details in the human pineal gland in the light of phylogeny, structure, function and chronobiological diseases. J Pineal Res 51: $17-43$.

Taylor D, Sparshatt A, Varma S, and Olofinjana O (2014) Antidepressant efficacy of agomelatine: meta-analysis of published and unpublished studies [published correction appears in BMJ (2014) 348:g2496]. BMJ 348:g1888.

van Bijsterveld OP (1969) Diagnostic tests in the Sicca syndrome. Arch Ophthalmol 82:10-14.

Vincent L, Cohen W, Delagrange P, Boutin JA, and Nosjean O (2010) Molecular and cellular pharmacological properties of 5-methoxycarbonylamino-N-acetyltryptamine (MCA-NAT): a nonspecific MT3 ligand. J Pineal Res 48:222-229.

Wiechmann AF and Rada JA (2003) Melatonin receptor expression in the cornea and sclera. Exp Eye Res 77:219-225.

Address correspondence to: Francisco Javier Navarro Gil, Departamento de Optometría y Visión, Facultad de Optica y Optometría, Universidad Complutense de Madrid, C/ Arcos del Jalón 118, 28037 Madrid, Spain. E-mail: fjnavarr@ucm.es 